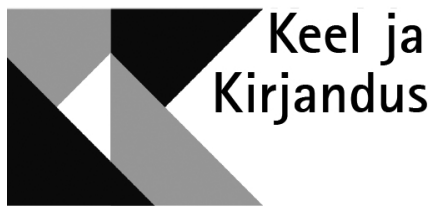

\title{
EBAÕDUS KOJUTULEK EESTI KIRJANDUSES
}

\author{
LEO LUKS
}

$\mathrm{K}$

oduigatsus on üks arhetüüpsemaid tundeid maailmakirjanduses. Paljud kirjandusteosed koosnevad põhiliselt koduigatsuse meeleolu lüürilisest kirjeldamisest, võimsaimaks sääraseks saavutuseks eesti luules julgen nimetada Ernst Enno luuletust „Kojuigatsus” („Nüüd õitsvad kodus valged ristikheinad...”). Siiski ei piirdu kirjandus üksnes igatsemisega; üheks süžeed kandvaks motiiviks läbi aegade ja kõigis žanrides on teekond kodu poole, kojutulek. Sõltuvalt teosest võib see olla heroiline-seikluslik, vaikne-mõtlik jpm, siia alla kuulub minu meelest isegi naasmiseks vajaliku sisemise meelekindluse hoidmine vangipõlves (nt „Robinson Crusoe” või arvukad kirjeldused lootuse säilitamisest koonduslaagris). Tegemist pole kirjanduse siseasjaga, Theodor Adorno ja Max Horkheimeri (2000: 65) väitel on „Odüsseia” kodu(maa) kaotuse ja taasleidmise pingutuse loona Euroopa tsivilisatsiooni alustekst. Küllap kehtib see üldistus ka ärkamisajal tekkinud eestikeelse kirjanduse kohta: Eesti kui koduilma avaram sfäär, ühine kodune maa luuletati kokku esmajoones isamaad ülistavates hümnides, kuid kindlasti andsid sellesse loomistöösse oma panuse ka kaugel viibinud laulikute koduigatsuse-manifestatsioonid (nt Lydia Koidula „Igatsus”, Carl Robert Jakobsoni „Kandke koju”). Spetsiifilisemalt kojutulekust kõneldes ei tasu unustada „Kalevipoja” lõpusalmi Kalevi kojutulekust, mis loob tugeva sümboolse silla kojutuleku ning ees seisva rahvusliku ülesehitustöö vahele (vrd Anna Haava luuletustega „Eesti kodu”, „Sääl kord kasvab kaunis kodu”).

Selles artiklis ei keskendu ma siiski kojutuleku sümboli rahvuslikule väele ega kõigile võimalikele modaalsustele ja tonaalsustele, mis asuvad kodu- 
igatsuse ja kojujõudmise vahel. Piiritlen uurimisobjekti kitsamalt selliste eesti kirjanduse luule- ja proosatekstidega, mille temaatiliseks fookuseks on tegelik kojutulek, kojujõudmine. Uurimus on artikli „Eesti kirjanduse kadunud kodu” (Luks 2014) mõtteliseks jätkuks, jäädes truuks seal avatud teoreetilistele lähtekohtadele (kodusus kogemushorisondina, kodutus selle horisondi tõrkena, poeetiline nimetamine tähendushorisontide erilist laadi tõrkena), millele siin osutan üksnes põgusalt.

Mitte üksnes „Odüsseia” ega paljude tänapäeva meelelahutuslike teoste põhjal, vaid ka argikogemusest lähtudes on paslik oletada, et igatseva inimese kojujõudmine peaks olema rõõmus ja pidulik sündmus, mis võiks moodustada teose kulminatsiooni, õnneliku lõpu. Vaadelgem selle selgituseks põgusalt minu eelnevate uurimuste varal fenomenoloogiliselt kojutuleku üldist struktuuri.

Olen varem (Luks 2013a, 2014) mitmetele filosoofidele tuginedes kaitsnud seisukohta, et kodusust tuleks mõista kogemuse horisondina, mitte teadvustatud objektina. Inimese eluilm jaguneb samaaegselt kaheks horisondiks, kodu- ja võõrilmaks, mis on omavahel ühendatud ja lähevad sujuvalt üksteiseks üle (kodu kui koduilma ruumiline kese, kodukant kui tuttavam naabruskond, sama emakeelt kõnelevate inimestega asustatud kodumaa, tuttavad naaberriigid jne). Olen väitnud, et kodusus jaguneb ru u milis eks ning intersubjektiivseks struktuurielemendiks (Luks 2013a: 413-414), sujuv üleminek kodususe ja võõruse vahel iseloomustab mõlemat elementi. Kogemushorisondid on omamoodi „nähtamatud asjad”, mida senikaua, kui nad toimivad, ei panda tähele, see kehtib ka kodususe kohta. Siiski on horisonte võimalik märgata ja objektiveerida, kuid siis lakkavad need horisondina toimimast - säärast katkestust olen nimetanud horisondi tõrkeks. Kõige avaramas tähenduses mõistan kodutust subjektiivselt kogetava olulise ajaliselt püsiva kodusushorisondi tõrkena (Luks 2013a: 415).

Antud eeldustest lähtudes on lihtne visandada kojutuleku kogemuse tekkimiseks vajalikud tingimused. Esitan siinkohal selle n-ö puhtaima juhtumi, kuigi lähtudes kodususe kahest struktuurielemendist ning koduilma/võõrilma erinevatest sfääridest annaks tuletada mitmeid vahevariante. Kojutuleku kogemuse käivitamiseks on esiteks mõistagi vaja viibida võõrsil, kodust eemal. Puhtaim olukord on säärane, kui eemalolek katab nii ruumilist kui ka intersubjektiivset aspekti, st ollakse võõrsil üksi, ilma kodukaaslasteta. Teis eks on vaja, et eemalviibija teadvustaks oma seisundit, objektiveeriks kodu - enamasti on selleks tarvis kas piisavalt pikka võõrsil viibimise ajalist distantsi ja/või asjaolu, et kodust ei lahkutud päris vabatahtlikult. Kol m a n d a kojutulekuks hädavajaliku tingimusena tuleb nimetada koduigatsust, võõrsil viibija peab tahtma naasta. See ei pruugi alati nii olla, näiteks võib laps kogeda põnevast suvelaagrist koju viimist vägivaldse sündmusena, sel juhul tekib temas koju naastes küllap kodusushorisondi tõrge, vajadus taas kodus n-ö sisse elada. Samuti võib inimene mingil põhjusel katkestada sidemed kodu või kodumaaga, kolida võõrsile ning üritada koduigatsuse kiuste uues kohas koduneda või identifitseerida ennast kodutuna, piiridel asujana (JanMohamed 1992). Juhul kui kõik kolm tingimust on täidetud ning koju naasmine on ka praktiliselt teostatav, saabki inimene kodutee jalge alla võtta. Teekonna vältel peaks igatseja ootusärevus üha kasvama, kuniks jõuab kätte kojutulek: 
naasmine tuttavasse, mis osutub tänu eemalviibimisele pidulikuks sündmuseks. Reisimine tundub olevat üks toimivamaid tehnikaid kodu pühitsemiseks, igapäevases rutiinis varjule jääva kodusushorisondi läbivalgustamiseks - see võib osaliselt seletada ka tänapäeva lääne inimestele omast kihku käia regulaarselt kaugetel maadel puhkusereisidel.

Artiklis „Eesti kirjanduse kadunud kodu” kirjeldasin, kuidas kirjandusteoses aset leidev poeetiline nimetamine on üks erilist laadi horisondi tõrge (Luks 2014: 733-735). Viitasin seal mitmel korral Martin Heideggeri poieetilisele kunstikäsitusele, mis päädib inimese maailmas asumise luulelisuse piiritlusega. Selgitasin seda asumise viisi, osutades Heideggeri nüüdseks ka eesti keelde tõlgitud esseele „Asi” (Heidegger 2017), kus mõtleja tõstab ühe argise asja - kruusi - igapäevastest kasutusseostest kõrvale ning näitab, kuidas selles koondub maailmanelistu (st taevas ja maa, surelikud ja jumalikud) ringmäng. Poeetiline nimetamine on üks, kuigi mitte ainus argielu horisontide peatamise menetlus, mille kaudu tuleb ilmsiks inimese avatus tundmatule, tema horisonte mõtestav-läbivalgustav loomus.

Hilise Heideggeri kunstiteoorias on keskne meeleolu pühalikkus: luuletaja nimetab püha ning luulet tõlgendav mõtleja mõtleb sinna juurde olemist (Heidegger 1978: 309). Just luule, st asjade poeetiline nimetamine pakub Heideggeri (1989) hinnangul inimesele vajalikku tuge viibimaks moodsa tehnika pühadust välistavas maailmas.

Eelneva lühikirjelduse põhjal võib väita, et kojutulek on kõige positiivsem, pühalikum viis kodususe kogemiseks, see on sündmus, mida tuleks luuletada hümni vormis, nagu teeb Hölderlin ning tõlgendab omakorda Heidegger (1971). Tuleb rõhutada, et inimese maailm ei koosne üksnes vahetult kogetud sündmustest, vaid samuti fiktsionaalsetest võimalikest sündmustest: meil on võimalik, enamasti küll teatavate reservatsioonidega, elada kaasa teiste inimeste, sh fiktsionaalsete tegelaste seiklustele; siinse artikli teemat arvestades peaks olema võimalik tunda rõõmu kojutulekust ilma tegelikult kodust lahkumata (oletan, et ka selline kaasaelamine, mitte üksnes pöörased seiklused, seletab „Odüsseia” ja selle „kloonide”, nagu nt Tolkieni teoste, populaarsust).

Kuidas on lood piduliku kojutulekuga eesti kirjanduses? Sääraseid hümne meie kirjanduses napib. Väidan esiteks, et vaatamata Kalevi kojutuleku lubadusele ${ }^{1}$ ühe eesti kirjanduse arhetüüpse sündmusena ning selle sündmuse emotsionaalse laetuse potentsiaalile on minu teadmiste põhjal kojutulek eesti kirjanduses (sh pagulaskirjanduses) küllaltki vähe ekspluateeritud kujund. Kõige tuntumaks kodu kujutamise viisiks eesti kirjanduses on hoopiski nostalgiline mälestus (vt Luks 2014: 740-742). Te i s eks väidan, et hoolika otsimise tulemusel leitud tekstid õnnestuvast-õnnelikust kojutulekust on jäänud meie kirjanduskaanonis varjule (nt Lydia Koidula „Kaugelt koju tulles”, Aleksander Suumani „Kojutulek”, Hando Runneli „Idüll”, Tõnis Lehtmetsa „Koju”, Bernard

1 Tasub mainida, et juba 1919. aastal ilmus Oskar Lutsu sulest ka tänapäeva lavastuste kaudu tuttav irooniline näidend „Kalevi kojutulek”, vähem irooniline ei ole Kalev Kesküla samanimeline luuletus; Kalju Lepiku luuletus „Mõru mõte” värvib motiivi suisa apokalüptiliseks. 
Kangro „Koduküla”2). Tuntud laulupeo-luuletustest meenuvad esmalt kaks kojutuleku teksti: Juhan Liivi „Ta lendab mesipuu poole”3 ning Ülo Vinteri „Kodulaul”. Üheks viljakaimaks kodusust positiivses võtmes kirjeldada üritavaks žanriks on lastekirjandus, kuid ka seal kirjeldatakse kojutulekut harva (nt Ly Kuninga „Kodu”, Ernst Enno „Poisid ritta”). Kol m a n d a k s väidan, et eesti kirjanduse paradigmaatiliseks kojutuleku juhtumiks on kadunud kodu nimetamine, kojutulek ei vasta eelnevalt kirjeldatud skeemile, vaid muutub imelikuks, kui mitte suisa õudseks. Selle väitega ei pea ma esmajoones silmas tekste, kus traagiliste sündmuste tõttu koju ei jõutagi (nt Marie Underi „Kojuminek").

Järgnevalt keskendun viimase väite edasiarendamisele, vaadeldes peale teoreetilist avangut paralleelselt kojutuleku kujutamist sõjajärgses pagulaskirjanduses (vt ka Kruus 2000) ning Kodu-Eesti luules; seejärel piiritlen tontliku kodukäija ja tühja kodumaja motiivi eesti kirjanduses ning viimaks vaatlen paari teksti varal paratamatult luhtuva kojutuleku kujutamist. Sotsiotsentristliku tõlgenduse ennetamiseks mainin, et kojutuleku veidrus eesti kirjanduses ei piirdu rahva suurte kannatuste perioodiga alates 1940. aastast, vaid ulatub ühtlaselt kirjanduse algusest tänasesse päeva. Kui Heideggeri (1971: 23) tõlgenduse kohaselt on kojutulek tagasipöördumine algupära lähedusse, siis Ernst Enno (2008: 102) luuletuses jääb see lähedus saavutamata:

Kui peita tahaks kodu sülle palge,

Kui onnnist muinasjuttu korrata -

Ja seisan vait, ei meelde tärka alge.

Ma nagu koormast pean algama. („Koju jõudes”)

Enne tekstivaatlusi peatun põgusalt ühe katusmõiste juures, mille abil saab üldistavalt kirjeldada kojutuleku veidrust eesti kirjanduses: selleks on ebaõdusus.

${ }^{2}$ Üks spetsiifiline grupp positiivset meelsust esitavaid tekste on tagalakirjanike 1944. aasta kojutuleku kajastamine. Sotsialistliku kunsti reeglid nõuavad võidukalt naasnutelt optimismi, vaatamata kaotustele-varemetele. Kirjanikud lahendavad ülesande enamasti eesseisvale ülesehitustööle truudust vandudes (vt Jaan Kärneri „Kojutulek”, Johannes Barbaruse „Jälle kodupinnal”, Mart Raua „Koduteel II”). Ideoloogilisest rõhuasetusest on puutumata Erni Hiire luuletus „Kodutee”, mis keskendub pühaliku sideme tekkimisele kodumullaga. Mõistetavatel põhjustel pole ükski viidatud tekstidest täna enam laiemalt tuntud.

${ }^{3}$ See luuletus ei vasta tegelikult kojutuleku tingimustele, kirjeldades suundumust isamaa poole; artikli lõpus näitan, et selle suundumuse kirjeldamise kohta on eesti kirjanduses leida rohkem positiivseid näiteid kui kojutuleku kohta.

${ }^{4}$ Sugugi mitte triviaalseks tekstiks, mis vääriks eraldi analüüsimist, on Oskar Lutsu „Nukitsamees”: selles leidub lisaks muinasjutule omasele ekslemise-seiklemise-kojujõudmise motiivile ka võora koduilma internaliseerimise probleem. 


\section{Ebawõdusus ja selle loomine kirjanduses}

Üritades tuua ühisnimetaja alla artikli järgmistes osades kirjeldatavaid kojutuleku veidraid luhtumisi eesti kirjanduses, ei ole ma leidnud paremat mõistelist üldistust kui ebaõdusus (sks das Unheimliche), nii nagu seda kirjeldab ühes lühikeses kirjatöös 1919. aastast Sigmund Freud (2014). Järgnevalt refereerin põgusalt Freudi tähelepanekuid ebaõdusa kogemuse mõningatest tekkemehhanismidest ning tema oletusi, kuidas kirjanduslike vahenditega see kogemus lugejas tekitada.

Saksa unheimlich on eesti keelde raskesti tõlgitav mõiste,${ }^{5}$ millel pole peatutud ka vähestes psühhoanalüüsi terminoloogia alastes käsitustes (Jüriloo 1994; Krull 1998). Vabalt rääkides peetakse selle all silmas emotsionaalset ebamugavust, veidrust, imelikkust, mis on suguluses hirmuga või suundub sinnapoole,${ }^{6}$ kuid pole siiski veel nii intensiivne. Miski täiesti võõras või üheselt ohtlik tekitab hirmu, kuid ebaõdusust tekitavad Freudi väitel just sellised olukorrad, mis on veidral moel tuttavad. „Ebaõdus pole tegelikult midagi uut ega võõrast, vaid miski, mis on vaimus tuttav ja põline ning on sealt võõrandunud vaid repressiooni tõttu" (Freud 2014: 22). Freud (2014: 8) tugineb oma määratluses Schellingile, kelle väitel ebaõdus on nimetus kõige kohta, mis peaks jääma saladuseks ja varjule, kuid on tulnud ilmsiks. Ebaõdus on seotud millegi ahistavalt tuttava kordumisega, mitteteadvusliku-instinktiivse domineerimisega, mis ületab naudinguprintsiipi (Freud 2014: 20) - Villu Kanguri lauluteksti sõnastuses: „Kõik on kahtlaselt kodune kõik on kohtlaselt tuttav”. ${ }^{7}$ Freud (2014: 11-12) ilmestab seda printsiipi nii elust kui ka kirjandusest pärinevate näidetega, muuhulgas analüüsib ta Hoffmanni õudusjuttu igal ööl naasvast Une-Matist, kes ähvardab pimestada lapse silmi. Isiklikust kogemusest toob ta esile linnas ekslemise juhtumi: üldiselt tuttavas keskkonnas jalutades korduvalt samasse kohta tagasi sattumise (Freud 2014: 18). Ebaõdususe tekitab just vältimatu kordumine, korduv sündmus ise (nt seismine tänavanurgal) ei pruukinud seda sugugi algselt olla (Freud 2014: 22). Lisaks on Freudi jaoks ebaõdus teisiku ilmumine, isiku topeldamine (2014: 16); surnud vaimude-tontide naasmise kartus ja kummituslik-imelik maja (2014: 23); kurjade kavatsuste ja erivõimetega isikud, hullus ja epilepsia (2014: 10). $\mathrm{N}$-ö tontlikkust-kummituslikkust üldistavalt tõlgendades jääb Freud (2014: 28) kordamissunni hüpoteesile kindlaks, seletades neid vanade allasurutud

${ }^{5}$ Ebaõdus on tõlkevaste, mis tundub küll kohmakas, kuid on siin-seal ilma pikema arutluseta kasutamist leidnud (nt Tomberg, Lopp 2008) ning jõudnud terminina ka kriitilise teooria kogumikku (Malpas, Wake 2015: 267). Alternatiivselt on käibel Ülo Matjuse tõlge pelutav (vt nt Heidegger 1999: 189-213), mille valimist on tõlkija ka korduvalt selgitanud (viimati Matjus 2012: 18-20). Matjuse vaste on lisaks sügavamale läbimõtestatusele ka tavakeeles suupärasem, kuid varjule jääb siinseski analüüsis oluline tähelepanek, et õduskodune ise naaseb eba-na (see seos on ka Matjusel siiski etümoloogiliselt sees: pelg kui varjav paik, kodu). Tuleb paraku leppida sellega, et vaevalt ükski võimalik tõlge annaks edasi saksa heim-tüve kõiki tähendusvarjundeid: kodune (heimisch), salajane (geheim) ning kohutav (unheimlich; vt Matjus 2012: 18).

${ }^{6}$ Heidegger (1979: 400) seostab meeleolude ehk häälestuste (sks Stimmungen) analüüsis ebaõdusust kõige tugevamalt ängiga (sks Angst).

${ }^{7}$ „Mina pean sambat tantsida saama”, https://sasslantis.ee/lyrics-singer_vinger-mina_ pean_sambat_tantsida_saama (27. IX 2017). 
animistlike uskumuste esilekerkimisena. Kokkuvõtlikult piiritlebki Freud (2014: 29) ebaõdusa kogemuse tekkimise tingimused nõnda, et selle tekitab kas lapseaja allasurutud komplekside või siis vanade primitiivsete uskumuste taaselustumine.

Freudi väitel (2014: 29) pakub kirjandus ebaõdususe loomise mehhanismide osas elust rohkem võimalusi. Ebaõdususe tekkimist on võimalik juba eos vältida - Freud toob näiteks muinasjutu žanri, kus igasugu erivõimed ja imed (nt Lumivalgekese surnust ellu ärkamine) on algusest peale võimalikud ega tekita lugejas ebaõdusust. Lugejas ebaõdusa kogemuse tekitamiseks on Freudi arvates hädavajalik, et kirjanik looks esmalt n-ö tavareaalsusega sarnase fiktsionaalse maailma (raami), kuhu ootamatult lisanduks mõni eespool kirjeldatud ebaõdus element. Kirjanik lubab lugejale pakkuda kainet tõde (st realistlikku kujutist) ja siis ikkagi murrab seda lubadust; selleks ajaks, kui lugeja tema võtte läbi näeb, on juba liiga hilja ning ebaõdus kogemus ongi tekkinud (Freud 2014: 30). Pinge kruvimiseks ja ebamäärasuse hoidmiseks on kirjanduses suur hulk kunstilisi võtteid.

Lisaks ebaõdusa kogemuse tekkimise tingimustele vaatleb Freud mõistet lingvistiliselt ning jõuab samale järeldusele nagu sisuliste näidete käsitlemisel: õdus (sks heimlich) on ambivalentne sõna, mille sees on ebaõdusa potentsiaal. Lisaks kodusele, tavalisele, tuttavale, taltsale tähendab heimlich ka pilgu eest varjatut, intiimset saladuslikkuse tähenduses. Nagu mõisteliselt, nii ka kogemuslikult toitub ebaõdus õdususest, on ühel või teisel moel selle alaliik (Freud 2014: 10).

Käesoleva artikli põhiväide - kojutulek eesti kirjanduses on valdavalt ebaõdus - jätab eksliku mulje, nagu võiks kojutulek olla või koguni peaks olema õdus. Õdususe mõistel on minu arusaamise kohaselt suur ühisosa kodususe mõistega, nii nagu ma seda eelnevalt piiritlesin, kuigi õdus äraolemine võib inimesel tekkida ka võõrsil (vt Epp Annuse (2003) mõtisklust kodu-koha-tundest). Sellest ühisosast lähtudes tundub mulle, et ka õdusust tuleb mõista kogemushorisondina, mitte objektina. Teataval määral on küll võimalik luua õdusat, kodust, hubast kirjandust (nt Oskar Lutsu Paunverelood), kuid sellisel juhul peab õdusus toimima taustana, „värvides” tegelasi ja sündmusi. Niipea kui kojutulek (või laiemalt kodu) on teemana kirjandusteose keskmes, ei saa seda teksti õdusaks ega koduseks nimetada. Eelnevalt polegi ma seda teinud, olen üritanud väita, et lugejate positiivne ootushorisont säärastele tekstidele on pidulikkuse-pühalikkuse tekitamine. Selle meeleoluloome põhivõtteks on igapäevaste asjade nimetamine nii, et kõik oleks teisiti kui muidu, argipäeva sekundid kuulutatakse imeks; kodu mõiste toimib argiseid elemente koondava ja mõtestava üldistusena (vt nt Suumani „Kojutulek”, „Neid igasuviseid sõite kodukanti”; Runneli „Idüll”; Peep Ilmeti „Kodune”). Säärase kirjanduse ning sellega seotud lavastuste funktsiooniks on kodususe taastootmine: argielu horisontides tekib pidulik tõrge, mille käigus neid ülistatakse ning niisugune sündmus (kas või nt aktus lasteaias, kus kuulajate lapsed laulavad lihtsat kodulaulukest) „värvib” kodusushorisondi sees edasi toimetavate inimeste meeleolu rõõmsamaks.

Ebaõdususe kui piduliku-pühaliku nimetamise vastandiga kohtumine katkestab argielu toimivuse püsivamalt, ilma seda taasloomata. Normaaltingimustel on koduilma ruumiliseks keskmeks kodu ning kodukaaslaste intiimsei- 
maks hulgaks seal elav perekond; juhtumid, mil selles keskmes katkeb kodususe toimimine, on psühholoogiliselt kõige rängemad, ebaõdusamad.

Nagu eelnevalt vaatlesin, on kojutulek argielulistel normaaltingimustel inimese elus väga elev ja positiivne sündmus, koduigatsusest kantud teekond koju on tugevalt „värvitud” rõõmsa-piduliku kohtumise ootushorisondi poolt. Kui see ootus ei täitu, kojutulek osutub ebaõdusaks sündmuseks, siis peaks selle kogemuse intensiivsus, psüühiline šokk olema veelgi tugevam. Kui nüüd kojutulekut kirjeldatakse kunstiliste vahenditega, siis loovad kunstikeele tihedus ja valitud sümbolite täpsus lugejas veelgi intensiivsema elamuse kui argielus. Kui aga naasmine luhtub, on ka tekkiv ebaõdusus tugevaim. ${ }^{8}$ Kõike seda pakubki meile eesti kirjandus: ta meelitab lugeja helgele koduteele, kuid erinevate võtete abil saavutatakse efekt, et kojujõudmises pole enam mingit helgust, vaid üksnes ebaõdusus.

\section{Ebaõdus kojutulek}

Minu lugemiskogemuse põhjal sobib Freudi ebaõdusa kogemuse loomise visand kojutuleku analüüsiks eesti kirjanduses nagu rusikas silmaauku. Just kodu tundub olevat see tuttav, mis peaks jääma unustusse, kuid loominguline kordamissund rebib selle ebaõdusana taas esile. Enne tekstinäidete vaatlemist visandan Freudi märkuste abil neid tekste ühendava ebaõdusa kojutuleku üldise narratiivse struktuuri.

1. Siin kehtib Freudi kummastuva reaalsusprintsiibi nõue. Kojutulek algab usutava kirjeldusega, mis teksti käigus ühel või teisel moel kummastub kõhedast unenäolisusest ühetähendusliku oudusšokini, mis esitatakse enamasti teksti puändina.

2. Kojutuleku-tekstides põimuvad orgaaniliselt Freudi mainitud lapsepõlvekompleksid vanade allasurutud uskumustega. Sageli vihjatakse tekstides, et minnakse ajas tagasi lapsepõlvekoju, kuid satutakse fantaasiaruumi, mis varieerub ebamäärasusest tontlikuni. Aset leiab põgus katkev kohtumine surnud vanematega või jõutakse tühja majja (kummitusmajja). Ka siis, kui otsene viide minevikulisusele puudub, muutub keskkond ohtlikuks, kummituslikuks, kindlasti tekib võõristus, kohtumine võõraga. Ühelt poolt võib see aset leida lüürilise mina kummitusega kohtumisena, kuid mis veelgi ebaõdusam: võõrus võib imbuda ka jutustava minategelase sisse. Seda nihet kannab kõige paremini mõiste kodukäija, mida on ebaõdusa kojutuleku puhul eesti kirjanduses korduvalt kasutatud. Koju saabuja osutub kodukäijaks, muundub pikkamisi selleks või vähemasti tekib lugejas selline kahtlus; naasja identiteet ei püsi ühtsena (vrd Freudi teisiku-motiiviga).

${ }^{8}$ Sellele oletusele on lihtne vastu vaielda, viidates asjaolule, et kunstilises kogemuses säilib vastuvõtjal üldjuhul kogetava sisuga teatud distants, mis toimib kogemuse intensiivsuse lahjendina. Teisalt võimaldab kunstiteos, eriti luuletus, süvenenud vastuvõtu korral keskenduda mingile teemale palju täpsemalt kui argikogemus, kus erinevad tähendused ja tähendushorisondid vahelduvad. Süvenemist, sisseelamist ja elamuste intensiivsust hõlbustab see, kui kirjanduses avanev puudutab lugejat isiklikult, eluliselt, st käivitab otseseid või sümboolseid paralleele tema eluga. Julgen oletada, et kadunud kodu ning kitsamalt rõõmsa kojutuleku võimatus on sedasorti teema, mis kõnetab paljusid lugejaid. 
3. Autori irooniline distants tegelaste ja olukordadega välistab mõne teksti lugemisel ebaõdusa kogemuse tekkimise, Freud (2014: 32) toob siin näiteks kummituste kujutamise Oscar Wilde'i „Canterville'i lossi vaimus”. Näidetena sobiks mainida ka Albert Kivika „Kodukäijat” ning Enn Nõu „Presidendi kojutulekut”. Kumbagi romaani pole minu hinnangul võimalik lugeda teisiti kui poliitilise pamfletina. Olgugi et Kivika romaanis on olemas mitmed ebaõdususele omased elemendid (peategelase fantastiline sattumine kodumaale, tontlik kohtumine surnud emaga jms), raamib kohtuprotsessina edastatud poliitiline vaidlus lugemiskogemust nii, et ebaõdususe võimalused ei avaldu. ${ }^{9}$ Pärast „Kodukäija” mõne peatüki lugemist kujuneb välja ootus teose struktuuri kohta, mis ka pidevalt täitub: kordub perioodiliselt farsilik kohtuprotsess, vaidlus pagulase ja kommunistliku režiimi vahel, milles osalevad ideelisteks koondkujudeks tihendatud inimesed. See on teose keskne sõnum ning ülejäänud peatükid, milles peategelane eksleb kord hirmsamates, siis jälle argisemates paikades, jäävad vahepaladeks enne järgmist istungit.

Vaadelgem esmalt variatsioone kojutuleku käigus asetleidvast kohtumisest võora(ste)ga. Selle kohtumise kujutamise paradigmaatiliseks näiteks on Kalju Lepiku luuletus „Nägu koduaknas” (1946).

Tahan suruda näo

Vastu koduakna mõranenud ruutu.

Kuulata tuttava käo

aastaid lugevat kukkumist

ja tunda,

et kodu ei muutu

aegade tuiskliivas.

Tuul undab.

Rohtunud rajal

sammud mind

rahutult viivad.

Magab kui unine lind

kodune maja.

Kas sama tuttavalt eit

ootab avatud uksel meid,

tuuli tallanud poegi?

Kartlikult astun.

Tuttava lepiku taga

vaikinud kägu.

${ }^{9}$ Sama peab ütlema Enn Nõu varasema fantaasiaromaani „Pidulik marss” (1968) kohta: seal valitseb samuti paroodiline tonaalsus (nt sooritab Eesti vabastamise heaks erioperatsiooni James Bond); lisaks keskendub sündmustik vabastussõjale, mitte isiklikele koju naasmise kogemustele. 
Koduaknast irvitab vastu

võõra verine nägu. (Lepik 2002: 11)

Kojutuleku ootusärev eesmärk on selgelt sõnastatud, kuid teekond muutub samm-sammult ebaõdusamaks. Rada on rohtunud, tulija on kartlik, eluaastaid lubav kägu ei kuku. Teekonna puändiks on majast vastu vaatav verine nägu, mida saab mõistagi tõlgendada poliitilise vägivalla metafoorina (vrd ptk „Kodu” Kivika „Kodukäijas”), kuid ka tondiga kohtumisena õudusloo vaimus (vt Suuman 1977: 99-100). Selline kojutuleku kujutamise viis ei ole omane vaid pagulaskirjandusele, vaid kerkib Kodu-Eestiski esile. Näiteks Mari Vallisoo luuletuses „Tuled koju” (1981):

Tuled koju - võõrad

ümber laua.

Hävitavad toitu kõigest väest.

Musta leiba. Ükski sind ei märka.

Ükski lusikat ei pane käest.

Hallid särgid. Kausis hapupiim on.

Kauss kesk lauda pehmest pärnapuust.

Üks on justkui kuskil-nähtud näoga.

See, kes praegu sättis valget juust.

Sa ei eksi. Tuhat aastat õigus

on sul teada - mina olen see.

Külmkapp ohkab. Keerad gaasi lahti,

Süütad, kallad kannu kohvivee. (Vallisoo 1995)

Tulija kodus on ees võõrad, esimese salmi põhjal võiks oletada, et tegemist on lihtsalt vägivaldsete sissetungijatega. Kuid see, et nad tulijat ei märka, häälestab lugeja juba ebaõdususe suunas: tundub ebausutav, et luust ja lihast röövlid nõnda käituksid. Teises salmis näemegi, et tulijad pole läbinisti võõrad: „Üks on justkui kuskil-nähtud näoga”, kes ongi kodukäija, naasnud Ebaõdus. Luuletuse viimane salm ei piiritle tundmatu, kodukäija identiteeti: „mina olen see". ${ }^{10}$ Kui pagulaskirjanduse levinud motiiviks on kojutuleku katkemine, tekst lõpeb kas võõra kohtamise šokiga, nagu Lepiku luuletuses, või sagedamini katkeb kojutuleku unelm ärkamisega võõrsil (nt Kangro „Kojutulek”, ${ }^{11}$ „Mälestused”, „Kodutee”), siis Vallisoo luuletuses avaneb võõrastega koos asumise perspektiiv - selle kogemuse poliitilised allusioonid vajavad vaevalt siinkohal selgitamist.

Vaadeldud kujutamisviis on kandunud edasi ka uusimasse kirjandusse, sarnane olukord avaneb Andra Teede (2014: 50-51) pealkirjata luuletuses:

\footnotetext{
${ }^{10}$ Säärase mõistu-ütlemisega meenub esmalt küllap Jumala vastus Moosese pärimisele: „Ma olen see, kes ma Olen” (2Ms: 3, 14). Hegelliku metafüüsika kohaselt on see puhas universaalsus, mis peitub negatiivsusena keele igas nimetamisaktis (vt selle põgusat analüüsi Luks 2016: 262-265).

${ }^{11}$ Õigupoolest on Kangrol kaks selle pealkirjaga luuletust, siinkohal viitan luuletusele, mille algusread on: „Ma tulen, ma tulen tuulte teel” (Kangro 2000: 108-109).
} 
sõidan siiski kodu poole

vahepeal kipub see ununema

kui piirile jõuame

selgub et enam

edasi ei pääse

regionaalpoliitika võlud

piirialadelt ei sõida

üle paari bussi päevas

mõne tunni pärast

ähvardab pimedaks minna

jalutan linna äärde

kummaline sügis

ühtegi autot ei sõida

hääletan siiski

ükski põld pole veel koristet

kuigi poed on täis jõulukinke

kui lõpuks tartusse pääsen

on minu kööki tekkinud

seltskond kunstnikke veiniga

panen koti nurka

kummaline sügis

ütlen tervituseks

keegi ei vasta

kontrollin end peegli ees

võib-olla ei jõudnudki koju

kõigist maailma paikadest

juhustest hetkedest kuhu kunagi jõuda

see üks kord kõigist kojujõudmistest

minu segadust ei märka keegi

akna taga ohkab vana vaher

taeva poole

ja hakkab pungi ajama

Esmapilgul tundub Teede luuletus kõige argisem võrreldes kahe eelmisega: Lepiku luuletuses kruvitakse ootus üles ning tekst lõpeb emotsionaalse plahvatusega, Vallisoo luuletuses kohtutakse vaieldamatult kodukäijaga, Teede koju on aga roninud kõigest kunstnikud veiniga. Ometi ei pane ka nemad millegipärast tulijat tähele - seda aspekti, mis on rõhutatud korduse abil („kummaline sügis”), on võimatu eirata. Luuletuse kahe esimese salmi põhjal tundub, et kirjeldatakse lihtsalt lüürilise mina hajevil reisimist, kuid imelik kohtumine kunstnikega muudab kogu mulje kõhedaks, ebaõdusaks. Ebalus süveneb, tulija kontrollib end peegli ees, seab enda kojujõudmise kahtluse alla ja jääb ikka märkamatuks. Viimases salmis hakkab akna taga punguma puu, mis kinnistab luuletuse kummitusliku üldmulje (alles äsja oli väl- 
jas ju kummaline sügis). Siin on kaks peamist tõlgendusvõimalust: kas tulija on sattunud kodu asemel kummitusilma (või luulude küüsi) või on hoopis ise muutunud enda teadmata kodukäijaks. Kunstiliselt õnnestunud kirjandusteos üksnes vihjab viimati mainitud lugemisvõimalusele, kuid ei paku selgust.

Teede luuletusest veelgi peenemalt hoiab säärast ebalust üleval Hando Runneli luuletus „Lähed kodust või tuled koju” (1976: 33):

\begin{abstract}
Lähed kodust või tuled koju, keegi pääd ei tõsta, ei kae, nõrk, nälginud oled, roju, ükski süüa ei paku, ei prae, lähed lebad luine sängis, naine nutuga lahutab meelt, ühe väsinud võilillelõhna nopid värava tagant teelt.
\end{abstract}

Intriig on kahe eelmise tekstinäitega sarnane: tulijast ei tehta välja. Olukorra muudab pingelisemaks see, et kui Vallisoo ja Teede luuletustes askeldasid kodus pooltuttavad kutsumata külalised, siis Runneli tekstis sellist motiivi ei ole. Loomulik on seega oletada, et lüürilisest peategelasest vaatavad mööda tema kodukaaslased, tema pere - kes need muud siis kodus on -, pealegi kinnistab seda lugemisviisi naise (siin küllap abikaasa tähenduses) mainimine. Lüürilisele sinale omistatakse ühelt poolt inimlikke tunnuseid: nõrkus, nälginud olek, võilillelõhna tundmine, kuid kui põimida need tunnused asjaoluga, et keegi „sinust” välja ei tee, kipub püsima tontlik üldmulje koju uitama tulnud surnust. Miks siis muidu naine nutab? Kuid nagu öeldud, püsib tekst ebaõdususe piiril, samuti võib selle põhjal konstrueerida kestva peretüli või üksteisest võõrdumise tõlgenduse.

\title{
Tontlik kojutulek: kodukäija ja kummitusmaja
}

Siiani vaadeldud tekstinäited üksnes vihjasid võimalusele, et koju tulija võib osutuda kodukäijaks. Kahtlemata on kodus käimise / kodukäija tähenduslik ambivalentsus nii mõnelegi kirjanikule vahendiks, mille abil väljendada (maa)kodust võõrdumise traagikat. Selgeimalt on seda pinget tähele pandud Runneli luules, kelle üks valikkogugi kannab pealkirja „Kodu-käija” (vt ka Talivee 2009), kuid see on esil ka paljudel teistel (Urve Karuksi „Pagulane”, Jüri Üdi „Ööpäev”). Ent eesti kirjanduses leidub tekste, kus kodukäimise tontlikkus ilmneb selgelt, enamasti puändi või sõlmitusena, sellised teosed paigutuvad vähemalt otsapidi õudusulme žanri. Lähtuvalt siinsest fookusest jätan vaatluse alt kõrvale klassikalised tondilood, mis kirjeldavad kohtumist kodukäijaga (nt Liisi Ojamaa novell „Kojutulek”, Jakob Tamme luuletus „Kodukäija”, Karl Eduard Söödi luuletus „Laadateel”), ning käsitlen üksnes juhtumit, milles koju tulija moondub tontlikuks kodukäijaks.

Selle juhtumi eredaimaks esindajaks eesti kirjanduses julgen pidada Friedebert Tuglase 1916. aastal ilmunud novelli „Kuldne rõngas”. Selles esinevad kõik ebaõdususe klassikalised elemendid. Kojutulek on peategelase jaoks 
algusest peale vastumeelne ja isegi tinglik: Jürgens naaseb ema surma järel kohustuse korras lapsepõlvekoju maja müüma. Ta ei tunne mingit koduigatsust, vaid pigem tülgastust porise asula, kehvas seisus rõske maja ning seal elava muldvana teenija vastu. Novelli esimene osa on kirjutatud valdavalt realistlikus võtmes, suure mahu võtab enda alla peategelase argiste mõtete edastamine. Lugejas tekib ootus, et kogu tekst jätkub ühe pahura mehe argiste sekelduste kirjeldamisega, kuid siis toimub äkiline pööre. Jürgensile meenub oma kunagine lapsepõlvetuba, mis on kinni tapetseeritud; teda haarab seletamatu kihk tuba vaadata ning ta murrab läbi tapeedi sisse (Tuglas 1971: 310-311).

Novelli teine osa toimib fantastilise loo võtmes: peategelane satub lapsepõlve, kohtudes toas õega, kellega koos minnakse aeda mängima. Peagi veereb aiast mööda suur kuldne ratas, mida asutakse jälitama. Ajamõõde hägustub: „Vahel tuli tal veel nagu läbi une meelde kodu, ema ja õde. Talle näis, nagu oleks ta ääretu kaua teel olnud. Kui uneks näis muutuvat elu." (Tuglas 1971: 314) Korduvalt rõhutatakse, et kõik on nii imelik, ${ }^{12}$ kuid mitte veel õudne. Teine osa lõpeb kordusega: Jürgens jõuab ekseldes jälle vanemate maja juurde, mis tundub kollases valguses imelik ning juba isegi võigas (Tuglas 1971: 315).

Novelli kolmas osa areneb juba õudusloo registris. Esmalt selgub, et vahepealse seikluse käigus on mööda läinud palju aega, Jürgens leiab toast juba lehkava hoidja-eide laiba (Tuglas 1971: 316). Novell jätkub peategelase hämara ekslemisega: ei ole enam öö ega päeva vahet, elu võtab viirastusliku kuju, mida autor ilmestab mitmete absurdsete detailidega. Samal ajal püüab Jürgens kogu aeg midagi meenutada (Tuglas 1971: 317). Ta teeb meeleheitliku katse siseneda taas seinatagusesse tuppa, „Sinna õnnemaale!” (Tuglas 1971: 320), kuid ust ei ole enam. Tapeeti maha kraapides leiab Jürgens hoopiski iseenda nekroloogi sisaldava ajalehe.

Viimane sündmus annab küll olukorrale ratsionaalse selgituse, kuid huvitaval kombel ei lõpe novell siinkohal. Jürgens nõustub küll suurema vastupanuta enda viirastusolendi-staatusega (Tuglas 1971: 321), aga jätkab oma ekslevat varielu. Peagi satub ta surnuaia juurde, kus juba novelli alguses esinenud jalutu sant sosistab kaaslasele: „Too mees on surnud!” (Tuglas 1971: 322). Alles selle ütluse peale meenuvad Jürgensile oma juba asetleidnud surma üksikasjad, uppumine turbalaukasse. Neid mälestusi heietades liigub ta uuesti laugaste vahele - „Kuis kõik on korduv!” (Tuglas 1971: 323) - ning upub uuesti, millega novell lõpeb.

„Kuldses rõngas” on esindatud terve rida tunnuseid, mida Freud kirjeldab oma essees kolm aastat hiljem. Peategelane jõuab ekseldes pidevalt tagasi samasse kohta - lapsepõlvekoju -, kuid maja pole õdus, vaid omandab üha enam kummituslikke jooni. Samuti on mängus isiku topeldamine ning surm: peategelane avastab novelli lõpus (kaks korda!), et on surnud iseenda teisik. Kordamissund väljendub nii onnetoa otsingutes kui ka juba aset leidnud uppumise kordamises (viimane toimub justkui automaatselt, Jürgens ei sõnasta seda väljapääsu otsimisena). Juba läbielatud surm on see ebaõdus kogemus, mis on ununenud ja peaks jääma varju, kuid tuleb uuesti esile. Samuti täidab

12 Hasso Krull soovitas eravestluses just sellise ambivalentse veidruse-seisundi ilmestamiseks tõlkida sks unheimlich eesti keelde imelikuks. 
novelli esimene osa seda Freudi reeglit, et reaalsus ei tohi olla algusest peale tühistatud, lugejat tuleb algul realistliku mulje tekitamisega veidi tüssata. Siinse uurimise seisukohalt on kõige tähtsam tõik, et loo ruumiliseks keskpunktiks, kus pisut imelik tunne kasvab üle õuduseks, on just peategelase kodumaja. Ei ole juhus, et peategelase variellu langemisega lõppenud retk osutus lapsepõlvekoju naasmiseks - kodu ise on novellis algusest peale ebaõdus.

Freudi tähelepaneku paikapidavus imeliku-kummitusliku maja ebaõdusust tekitavast efektist ei vaja küllap pikemat vaagimist - tühi imelik maja (olgu siis hüljatud kodu või päris võõras) on õuduskunsti kõige levinum sündmuspaik (vt Curtis 2008; Vidler 1987). Ka eesti kirjanduses kujutatakse hüljatud majaga kokkupuutumist valdavalt ebaõdusana, enamasti visandatakse sel puhul fantaasiapilt maja juurde kuulunud elanikest, nende tegevustest ja lahkumise põhjustest ning resümeeritakse olukorra ebaloomulikkus:

\author{
Mõtted rühmuvad su ruumes \\ rambasrasked lõuka lummas, \\ taandumata tares tummas. \\ Need on sõnadeta suud, \\ kodukäijad kohatruud. („Unund hoone”, Sööt 1968: 98) \\ ja õudne lahti pääseb kisa \\ mu ammu kinninöörit kurgust: \\ Ma tahan elu! tuulte kargust! \\ Võib’s tühjus olla elus isaks? („Tühi maja”, Visnapuu 1965: 64) \\ Eksisin suuskadel sõidetud radadelt, \\ tabasin, Eesti, su varjatud valu. \\ Valgete lumiste nõlvade taga on \\ üksikud hüljatud talud. („Hüljatud talud”, Laht 1993)
}

Tühja maja ebaõdusus võib areneda edasi tontlikkuse suunas (nt Juhan Jaigi „Rehevare”). Tuglase „Kuldse rõngaga” sarnaselt kujutab seda võimalust Rein Raua luuletus „Tühi maja”. Lüüriline mina eksleb tühjas majas, mäletamata, kes ja kus ta on, ometi tundes meenutamise sundust. Luuletuse lõpus ebaõdus saladus meenubki: „veel kui kustunud siin polnud sära / tapsin ennast selles majas ära" (Raud 1995).

Nagu eespool põgusalt viitasin, kasutatakse tühja maja kujundit teiste võimaluste kõrval kojutuleku luhtajana pagulaskirjanduses, ainuüksi Bernard Kangrol on antud motiivil vähemalt kolm küllaltki sarnast luuletust („Kojutulek”, ${ }^{13}$ „Hiline kojujõud”, „Tühi tare”). Need avavad ebaõdusa nihestatud aegruumi: pehkinud kodumajas põleb 30 aastat tagasi süüdatud lamp („Kojutulek”), tühja rehetuppa jõudmisele eelneb kummituslik trampivate jalgade kuulmisaisting („Hiline kojujõud”), majas on ka heledal südasuvel pime („Tühi tare”).

${ }^{13}$ Pean silmas teist samanimelist luuletust (Kangro 2000: 280), mitte eespool viidatut. 


\section{Kojutuleku paratamatu luhtaminek}

Seni olen vaadelnud põhiliselt tekste, kus kojutulek on esmalt kantud pühalikust ootusest või äärmisel juhul argirutiinist (Tuglase, Vallisoo ja Teede näidetes), mis luhtuvad mingi imeliku sündmuse tõttu: võõra(ste) asumine kodus, kodumaja kõhe tühjus või tulija enda kummastumine kodukäijaks. Järgnevalt käsitlen kaht sarnase süžeega teksti, mis ei sobitu eelnevalt visandatud struktuuri ja milles kojutulek on veelgi imelikum.

Peet Vallaku 1921. aastal ilmunud lühike novell „Hulkur” (1983) on palju salapärasem kui tema poliitilist põgenikku portreteeriv lühiromaan „Hulgus”. Loo süžee on lühidalt järgmine. Ühel sügisõhtul ilmub tallu hulkur. Ta ööbib hanekongis ja nosib kaasa võetud toitu, varude lõppedes astub ka tuppa, kus talle armu pärast mõnel päeval süüa antakse (Vallak 1983: 12). Kuna hulkur ei lausu majarahvale kogu sealoleku aja jooksul sõnagi (ometi pole ta tumm), vihastab selline olek peagi peremehe välja ning ta kihutab hulguse minema (Vallak 1983: 14). Ometi on kutsumata tulija mõne päeva pärast hanekongis tagasi ning kuigi kohale kutsutakse sandarm, naaseb hulkur arestimajast vabanedes jällegi tallu (Vallak 1983: 15-16). Novell lõpeb sellega, et hulgus ronib pööningule ja poob ennast üles ning puändiks selgineb ka tema seos taluga: „Ta suri oma isamajas.” (Vallak 1983: 17)

Tüütu hulkuri osutumine kunagiseks perepojaks oleks võimas puänt, kuid novell pole üles ehitatud üllatuse tekitamisele. Ootamatu lõpplahenduse andnuks selline väljendusviis, kus hulkurit kirjeldatakse neutraalse jutustajahäälega ning majarahva perspektiivist, kuniks vaadeldu omandab lõpus subjektsuse ja eluloo. Kuid novelli vaatepunkt kõigub hoopiski jutustajahääle ja hulkuri sisemaailma vahel, majulisi kirjeldatakse valdavalt läbi peategelase silmade (mõnes üksikus kohas edastatakse pererahva hinnanguid, kellele sissetungija tundub veider, imelik; Vallak 1983: 13, 16). Hulkur pole nimetu vari, juba esimeses lauses tutvustatakse teda nimepidi, Surbikuna, ning paari esimese lõiguga tehakse selgeks, et tegemist on naasmisega 20 aasta järel. Surbiku lapsepõlvemälestuste edastamine (Vallak 1983: 12-13) vihjab selgelt novelli lõpus välja öeldavale seosele.

Mis on Surbiku loo mõte, moraal? Miks ta tuleb ja kangekaelselt kunagise kodu juures püsib? Novellis ei avata peategelase käitumise üldisi motiive. Tegemist ei ole otsese etteheitega ebaõiglaselt võorrandatud kodu tõttu (nagu Kivika „Kodukäijas” või Enno luuletuses „Miks jätsid talu võõrale”) - novelli algusridades öeldakse, et juba 20 aasta eest oli Surbik lahkunud kerjusena (Vallak 1983: 8). Ta ei lausu majarahvale sõnagi, ei tunnista oma kunagist seotust paigaga, kuid ometi vihastab, kui peremees kummalise vaikija minema kihutab (Vallak 1983: 15).

Tuleb öelda, et Surbiku naasmine ja käitumine on absurdne, mõttetu, irratsionaalse kordamissunni näide, omamoodi Sisyphose töö. Lähtudes artikli algul osutatud Adorno ja Horkheimeri tähelepanekust „Odüsseia” kui tuumteksti kohta, tekib kiusatus tõlgendada Vallaku novelli omamoodi antiodüsseiana lääne tsivilisatsiooni allakäigu faasis. Võrdluse aluseks on kojutulek 20 aasta järel, kuid kõik muu on vastupidine. Odysseus naaseb oma kodukaaslaste juurde - kuigi need on paljugi muutunud ja vajavad harjumist - ning paneb oma kangelasvõimete ja isandaõigusega maksma logiseva korra; 
Surbik naaseb väeti võõrana, ilma mingi legitiimse nõudmiseta, inimeste juurde, kes teda ei tunne. Odysseus hoopleb oma staatusega ja ähvardab majavõõraid, algul vihjamisi (Homeros 2006: 230, 238), hiljem avalikult (Homeros 2006: 284); Surbik vaikib, kuna tal pole staatust, mida väljendada. Odysseuse tunneb ära esmalt vana koer, kes seejärel sureb erutusse (Homeros 2006: 226); Surbik näeb pärast esimest hanekuudis magatud ööd, kuidas peremees poob oma koera üles (Vallak 1983: 10), kuid mõistagi pole poodu müütiline 20 aastat elanud loom. Odysseus taastab oma hiilguse veriste tapatalgutega, hukates kõik oma naise peigmehed ning nendega koostööd teinud teenijad (Homeros 2006: 283-295); Surbik poob ennast vaikselt üles. „Odüsseia” kuulutab lääne kirjanduse alguses kodu, kojutuleku ja korra võimalikkust; Vallak näitab kõigi nende kategooriate luhtumist.

Veelgi reljeefsemalt kordub kojutuleku ette teada olev luhtumine Merca luuletuses „Saabumine” (Jääger 1989: 46-47). Kui Aleksander Suuman (1977: 99) kasutab tontlikust kojutulekust luuletades antimotona Enno „Kojuigatsust", siis Merca lõimib eesti luule tuntuima koduigatsuse-teksti parafraasina oma luuletusse:

Nüüd kodus õitsvad valged ristikheinad, on soojas tuules tunda nende lõhna.

\& lookleb rada läbi ristikheina -

siit tulen mina: pöetud, luuni kõhna.

Kui Enno luuletuse koduigatsus on hell romantiline tundmus, siis Merca näitab kaasajale omases räiges võtmes, mis juhtub igatsuse realiseerimisega. Luuletuse esimene salm pakub eespool vaadeldud klassikalise situatsiooni, vaevatu kõnnib kodurada. Kuid üles ei ehitata pühalikku ootust, mis hiljem luhtuks, vaid saabumise ebaõdusus on ette teada:

Ma tean, et majas keegi mind ei oota, mu emale on leitud palju parem paik, all pärnade

\& surnuaia kaardilt

on kustutatud veel üx valge laik.

Kui Vallaku „Hulkurit” võiks tõlgendada nii, et saabuja ootab sisimas imet, et võõrad majulised võtaksid vaikija puhtast inimarmastusest omaks, siis Merca luuletuses puudub isegi positiivse ootuse vine. Järgmine salm täpsustab, et tegu pole naasmisega võõraste keskele, vaid tühja majja:

Näe, majatrepp! Ma avan paokil uxe.

... Kõik viidud siit. Ta tühi kui mu hing.

Kesk kõrget tuba kõlkumas on keha...

Truu sõber Pontu!!

Kaelas nöörist ling.

Tühja kodumaja ebaõdususele lisandub õõvastava detailina poodud koer. Kui Vallaku novellis mõjus pererahva koera poomine sündmustikku kummas- 
tava episoodina, mis vihjas loo lõpplahendusele, siis Merca luuletuses on poodud looma ja tulija vahel intiimne side, mida süvendab järgmine salm:

Ma alla võetan koera kange keha.

On liha juba lahti luude pääl...

Toa nurgas kahekesi endal' teeme koha.

Joon viina, paitan sõbra külma pääd.

Kui üldiselt on tühja lagunenud (kodu)majja sattumine eesti kirjanduses sündmuseks, mis põhjustab tulijas õuduse šoki, siis Merca algusest peale madalal energianivool toimiv luuletus on erand. Levinud kodususkujutelmade raames oleks vale öelda, et tulija koduneb, kuid ometi võtab ta koos surnud kaaslasega majas koha sisse, nähtu ei sunni tulijat põgenema ega haihtu meeleolupilt viirastusena. Luuletuse lõpp viib meid tagasi algusse ning aktualiseerib veel kord Enno koduigatsuse:

Siin kahekesi tühjad, surnud, kõhnad...

on nurgas mees \& koer \& nende leinad.

Toob tuulehoog mu ninna mingid lõhnad

... nüüd kodus õitsvad valged ristikheinad!

Merca luuletuses avanev resignatsioon seab küsimärgi alla romantilise pühaliku kojutuleku võimalikkuse: ehk on üksildane varemetes asumine moodsa aja normaalseisund, millega inimene peab harjuma (vt Luks 2013b). ${ }^{14}$ Neid implikatsioone vaen järgnevalt artikli kokkuvõttes, selle alapeatüki lõpetuseks pakun ühe võimaliku tõlgenduse luhtuva kojutuleku mõtestamiseks. Vaadeldud tekste võib käsitada peale irratsionaalsele naasmissunnile allumise ka sümboolsete retkedena tulla koju (kodumaale) surema olukorras, kus kodutu eksistents osutub väljakannatamatuks. Selles valguses pole Vallaku ja Merca tekstid erandlikud, sama motiiv kordub mujalgi (nt lõpeb Ridle surmaga August Jakobsoni „Vaeste-Patuste alev”, vt ka Söödi luuletust „Kadunud poeg”, Lepiku luuletust „Mu kodumaa”).

\section{Mõned järeldused}

Üritasin artiklis näidata, et eesti kirjanduses kujutatakse kojutulekut valdavalt imeliku, ebaõdusana. Analüüs kaitses minu üldisemat teesi kodu ilmnemisest eesti kirjanduses kadununa. Teen siin uuritud fenomeni kohta mõned üldistavad järeldused.

${ }^{14}$ Pikemat analüüsi vääriks resigneerunud naasmise avaldumine muude tegevusliinide vahel Tammsaare „Tõe ja õiguse” 5. köites. Lapsepõlvekoju „asumisele” naasnud Indrek jääb seal kogu raamatu vältel imelikuks, ebaõdusaks elemendiks, kõrvalseisjaks kodu ja võõruse piiril (elutseb saunas vana isa juures, kaevab erakuna kraavi, jäädes isegi isale tõeliseks mõistatuseks, vt Tammsaare 1969: 323). Samamoodi on Indrekule ebaõdus Vargamäe, kust on kadunud pea kõik lapsepõlvemaa mälu-pidepunktid (vt Tammsaare 1969: 18-23). Ometi pole Indrek läbinisti võõraks muutunud kodukäija, mitmel korral osaleb ta aktiivselt olulistes kriitilistes sündmustes (jõe süvendamise teemaline koosolek, Tiina ründamine soos, õetütre Elli lohutamine Oti surma järel). 
Esiteks, me ei tohiks piirduda kojutuleku luhtumise käsitlemisel kirjanduse sotsiotsentristliku tõlgendusega, olgugi et eesti (kirjanduse) ajalugu suisa pakatab säärastest seletusviisidest. Rahvusliku ärkamisaja vaimus võib kojutulekut tõlgendada kitsalt rahvuse jõudmisena omariiklusse (Kalevi kojutulek, Haava „Sääl kord kasvab kaunis kodu”, „Eesti kodu”) ning jätkata seda käsitust XX sajandi teise poole kirjanduses, kus luhtuva kojutuleku kujutamise raskuspunkt asub pagulaskirjanduses (Kodu-Eesti kirjandusele, eriti etnosümbolismile jääb kujutada võõra sissetungimist koduilma ja sellest tulenevat kodus püsiva kodutuse meelestust). Säärase kitsendava tõlgenduse vastu räägivad mõned siinse artikli tekstinäited nii XX sajandi katastroofi eelsest ajast (Vallak, Tuglas) kui ka taasiseseisvumise järgsest ajast (Teede), kus poliitilise allegooria tasandit ei paista olevat.

T e is eks julgen mõnevõrra spekulatiivselt laiendada tähelepanekut eesti kirjandusest kaugemale. Väidan, et kirjanduse pärisosaks ei ole kujutada kodusust, tavalisust, vaid tekitada tõrkeid argises eluilmas. Üheks harvaesinevaks tõrkeks on küll ka kodu nimetamine pidulikus hümnis, kuid säärased tekstid vajavad kunstilise elamuse tekkimiseks enamasti spetsiifilist lavastust (laulupidu, aktus vms). Õnnestunud kojujõudmise kohta pole eesti kirjanduses peaaegu üldse tekste.

Kahtlen, kas kojujõudmise õdus idüll saab üldse olla kunstiliselt kõrgetasemelise kirjandusteose kandvaks teemaks. Vahest pakub säärast kogemust Euroopa tsivilisatsiooni alustekstiks nimetatud „Odüsseia”? Odysseuse kojujõudmisega eepose lõpuosas kaasnesid esiteks laiaulatuslikud tapatalgud, mille käigus ei notitud maha üksnes ülbed peigmehed, vaid ka terve rida nendega rohkemal või vähemal määral koostööd teinud isikud. Veresaun põhjustab hukkunute lähedastes kättemaksumeeleolusid ning ähvardab veelgi laiemas mahus jätkuda, üksnes jumalanna Athena sekkumine peatab vägivalla (Homeros 2006: 319). Teiseks ei tunne ka kõige lähedasemad inimesed Odysseust ära - ta peab nii oma naise (Homeros 2006: 300-301) kui ka isa (Homeros 2006: 314) veenmiseks lahendama oma isikut tõestavaid mõistatusi. Kangelase kõrgendatud autunne ja kalduvus hybris'ele on muidugi eepose kirjutamise ajastule omane nähtus ning küllap on üle laipade kojujõudmises tänaseni mingi seletamatu võlu (miks muidu kordub see süžee nüri järjekindlusega märulifilmides), kuid õdusaks on seda raske pidada. Parem pole minu hinnangul lugu ka kuulsa piiblilooga kadunud pojast (Lk 15: 11-32): olgugi et isa selgitab seal nördinud kodukaaslastele, miks ta laristajast poega pidusöögiga vastu võttis, ning isale jääb loo lõppedes viimane sõna, pole sellega tingimata öeldud, et selgitus osutus veenvaks ja lepitas vimmapidajad.

Miks ei võiks siis olla kirjanduse pärisosaks kodusus, õdusus, sh rõõmus ja igapidi sujuv kojutulek? Miks ei pääse kirjanik vaimsest eksiilist (vt nt Haava „Suures ilmas koduta”, „Ma tunnen inimesi, kellel kodu on”; vt ka Kronberg 2001) ning peab parimal juhul sealt igavesti tagasi pöörduma (Gadamer 1993)? Olen üritanud neile küsimustele oma varasemates uurimustes vastata kirjandusele omase ei-lisuse kontseptsiooni varal (vt eriti Luks 2015), paraku nõuaks nende mõttekäikude kordamine rohkelt trükiruumi. Lühidalt öeldes väidaksin Maurice Blanchot'lt väljendit laenates, et kirjanduse keel on tehtud rahutusest (Blanchot 2014: 128), kirjandus tõmbub ebaõdususe suunas. 
Miks tõmbub kirjandus ebaõdususe poole? Jättes kõrvale ontoloogilised spekulatsioonid kirjanduse ei-lisest loomusest, võime sellele küsimusele läheneda ka inimloomuse üle arutledes. Ehk on ebaõdusus, kodutus, pidev puudus inimeseks olemise vältimatu tunnus? Nõnda tõlgendavad inimest psühhoanalüütikud, ennekõike Lacan ja tema järgijad. Samamoodi mõistab inimest Martin Heidegger vähemalt 1920.-1930. aastate töödes: inimene ei neeldu omailma, vaid on avatud maailma võõrusele, sestap on talle pärisomane seisund ängistus, täielik mitte-kodusus (vt Luks 2013b: 1113-1118). „Kodukäija inimen vaid ja kodukäijate verest", nii on inimest piiritlenud Henrik Visnapuu (1964: 398) luuletuses „Ülestõusmise pühal” ning Ülo Matjus (2012: 19) on oma pelutava-tõlkevastest lähtudes Heideggeri varal üldistanud: „inimene on peletis". ${ }^{15}$

Moodsa kirjanduse äärmuses (nt Kafka, Beckett) sünnivad ebaõdusad ruumid, kust pole võimalik välja pääseda, iga püüdlus luhtub ning kodu jääb paineks, mis peaks meenuma, kuid isegi ei meenu. Mõistagi ei saa kogu kirjandus koonduda säärasesse äärmusse, nii nagu inimene ei saa oma elus koonduda üksnes transtsendentsi poole. Nii inimelu kui ka kirjandus pendeldavad kodususe ja võõruse-ebaõdususe vahel. Olen varem lühidalt väitnud, et kõige viljakamaks viisiks kirjanduses on kaotatud (lapsepõlve)kodu nostalgiline meenutus (Luks 2014: 740-742). Kojutuleku käsitlus siinses artiklis näitas, et kui üritada vältida ajaviitekirjanduslikku idülli, võib saabumine areneda ebaõdusast õudseks, kohutavaks kogemuseks. See juhtub siis, kui asutakse kirjutama kojujõudmist, kuid on ka mõned võimalikud viisid kirjutada kojutulekust nn positiivses võtmes, pühalikult. Need viisid võtab kokku Heideggeri ütlus Hölderlini eleegia „Kojutulek” tõlgendamisel: eleegia ise ongi kojutulek (Heidegger 1971: 25; vrd ka George Steineri (2008) analüüsiga tekstist kui kodumaast). Teisisõnu, kirjandusteos ei tohi kujutada kojujõudmist, kirjeldada tuleb üksnes kojutulekut. Selle võtte struktuursed-temaatilised võimalused, mis vääriksid pikemat analüüsi, avanevad aeg-ajalt ka eesti kirjanduses ning tunduvad olevat järgmised:

1. Kujutada teekonda, koduteel viibimist ning teelise pühalikku ootusärevust ja kojujõudmise lubadust (nt Kangro „Kodutee”, „Me lähme koju”; Haava „Kodupoole”; Ralf Parve „Laul kaugest kodust”). Sellise võtte tipuks julgen pidada Visnapuu (1964: 457-460) luuletust „Kodu udun”, kus öise kojumineja ekstaatilises hinges hajub kogu tajuväli: maailm on vaga, kaugus on kohevil, kummuli taevad, jõgi on piiritu lai (Visnapuu 1964: 458-459). Sellise virvarri kohta ütleb luuletaja küll, et „Lummutet maailm, jube ja ülev”, ning laseb tulija ette ilmuda ka kummitusel, kuid meeleolu ei võta ebaõdusat pööret: kummitus kaob kärata, „Kõik on kojutulejal mittemidagi”, ning tulija tunneb eksimata teed (Visnapuu 1964: 459).

Niisugust kirjutusviisi leiab isegi uusimast popkultuurist, vt nt ansambli Metsatöll ühisloominguna valminud laulu „Kuni pole kodus, olen kaugel teel". ${ }^{16}$ Võtte alaliigina võib esile tuua teosed, kus kodutee katkeb traagilistel

${ }^{15}$ Lähtudes teisest, selleski artiklis omaks võetud ebaõdususe tõlkevastest, võib öelda, et inimene on ebard: ebaleja, ebaõdususe tundja, kes ei neeldu looma moel omailma, vaid viskub ootuste ja hirmudega tuleviku suunas, ängistudes luhtunud võimalustest.

${ }^{16}$ Tekst: https://sasslantis.ee/lyrics-metsatoll-kuni_pole_kodus_olen_kaugel_teel (27. IX 2017). 
põhjustel (nt Underi „Kojuminek”); mõnikord pakub lepitust kujundlik ülekanne surmast hinge kojujõudmisena (nt Koidula „Sügisemõtted”; Enno „Üks hing on koju läinud").

2. Kirjutada kutse vormis, muuta tekst kojukutseks (nt Enno „Oh, jõua koju!”; Runneli „Idüll”; Kangro „Kojukutse”, „Kojukutsuv hääl”; Jürgen Rooste „Kojukutsumise laul”). See võimaldab jätta kõrvale saabumisega seotud probleemid ning esitada kutsuvat kodu idüllilisena. Kutse võib võtta ka traagilisi või õudseid toone, koju kutsuda võib teadmata kadunuid või surnuid (nt rahvalaul „Itk” Pantokraatori esituses ${ }^{17}$ ).

3. Kirjutada kojutulekust tulevikulubadusena või täitumata võimalikkusena. Selline võte on tuttav vähemalt „Kalevipoja” lõpust ning leiab mitmeti kordamist (nt Haava „Sääl kord kasvab kaunis kodu”; Underi „Põgenik”). Eriti just pagulaskirjanduses sulavad tingimuslikku naasmist kujutades kokku kodu ja kodumaa - esitatakse naasmislubadusi kodumaa okupatsioonist vabanemise puhuks (Lepik „Odüsseia”).

4. Kirjutada kojujõudmise hetkest, peatuda kodulävel ning jätta kujutamata taaskodunemise raskused, lõhe ootuste ja tegelikkuse vahel (nt Erni Hiire „Kodutee”; Suumani „Kojutulek”). Kojujõudmine võib olla ka õnnis unelm, mis kestab teksti lõpuni (Underi „Nägemus”). Siiski on see võte kõige ohtlikum, seletamatu ebaõdususe koorem on kerge tekkima (nt Enno „Koju jõudes”; Arved Viirlaiu „Tagasitulek”; vrd ka Mahavoki tuntud lauluga Madis Trossi sõnadele „On läinud aastad”).

Lõpetuseks mainigem veel üht loomingulist võimalust: kuulatada küll kojukutset, kuid öelda sellele selge $e i$, tunnistada eksiili loomeruumina. Selline hoiak kumab läbi Karl Ristikivi loomingust, mitte üksnes ekslemisena võõras ruumis „Hingede öös”, vaid samuti korduvalt välja öeldud manifestina tema ainsas luulekogus „Inimese teekond” (Ristikivi 1990: 7, 9, 10):

\author{
Rändaja, mine! \\ Ja kui sa kord jõuad \\ koju, siis ütle, \\ et mina jäin maha, - \\ ei, mitte teele, \\ sest teed ei ole. (Ristikivi 1990: 52)
}

\title{
Kirjandus
}

Ad orno, Theodor, Horkheimer, Max 2000. Dialektik der Aufklärung. Philosopische Fragmente. Frankfurt am Main: Fischer TB-Verlag.

Ann u s, Epp 2003. Kodu-koha-tunne. - Looming, nr 8, lk 1250-1252.

Blanchot, Maurice 2014. Kirjandus ja õigus surmale. Valik tekste. Tlk Anti Saar. (Avatud Eesti Raamat.) Tallinn: Varrak.

C u rtis, Barry 2008. Dark Places. The Haunted House in Film. London: Reaktion Books.

E n n o, Ernst 2008. Rändaja õhtulaul. 2. tr. Tartu: Ilmamaa.

${ }^{17} \mathrm{https}: / /$ www.youtube.com/watch?v=S0F0hOttpj0 (27. IX 2017). 
Freud, Sigmund 2014. Das Unheimliche. Studio Roma. http://www.studioroma. istitutosvizzero.it/wp-content/uploads/2016/01/ISR_StudioRoma_Freud_DE.pdf (27. IX 2017).

Gad a mer, Hans-Georg 1993. Heimat und Sprache. - H-G. Gadamer, Gesammelte Werke. 8. kd. Ästhetik und Poetik. Kunst als Aussage. Tübingen: J.C.B. Mohr (Paul Siebeck), lk 366-372.

Hei de g ge r, Martin 1971. Erläuterungen zu Hölderlins Dichtung. Frankfurt am Main: Klostermann.

Hei d e g g er, Martin 1978. Wegmarken. Frankfurt am Main: Klostermann.

Hei d e g g e r, Martin 1979. Prolegomena zur Geschichte des Zeitbegriffs. Gesamtausgabe, II. 20. kd. Frankfurt am Main: Vittorio Klostermann.

He i d e g g e r, Martin 1989. Küsimus tehnika järele. Tlk Ülo Matjus. - Akadeemia, nr 6, lk 1195-1222.

Hei d e g g e r, Martin 1999. Sissejuhatus metafüüsikasse. Tlk Ülo Matjus. (Avatud Eesti Raamat.) Tartu: Ilmamaa.

He i d e g g e r, Martin 2017. Asi. Tk Märt Väljataga. - Vikerkaar, nr 1-2, lk 60-74. Ho m e r o s 2006. Odüsseia. Tlk August Annist. Tallinn: Varrak.

J a n M o h a med, Abdul R. 1992. Worldliness-Without-World, Homelessness-asHome: Toward a definition of the Specular Border Intellectual. - Edward Said: A Critical Reader. Toim M. Sprinker. Oxford: Blackwell, lk 218-241.

Jääger, Merle 1989. MercAmerka. Teine Ameerika-valimik. Scarborough: Maarjamaa.

Jürilo o, Alo 1994. Väike psühhoanalüüsi sõnaraamat. - Akadeemia, nr 8, lk 1757-1790; nr 9, lk 2021-2046.

Kangro, Bernard 2000. Kojukutsuv hääl. Tallinn: Eesti Raamat.

Kronberg, Janika 2001. Kirjanik kui pagulane? - Keel ja Kirjandus, nr 2, lk $122-124$.

Krull, Hasso 1998. Psühhoanalüütilised mõisted ja nende tõlkeprobleemid. Lacanlik vaatepunkt. - Keel ja Kirjandus, nr 9, lk 597-605; nr 10, lk 674-679.

Kruus, Oskar 2000. Koduskäijad eesti pagulaskirjanduses. - O. Kruus, Tinatähtedega taevas. Tallinn: Virgela, lk 166-187.

Laht, Uno 1993. Hüljatud talud. - Sõnarine. Eesti luule antoloogia. 3. köide. Koost Karl Muru. Tallinn: Eesti Raamat, lk 329.

Le pik, Kalju 2002. Valguse riie ei vanu. Tartu: Ilmamaa.

Luks, Leo 2013a. Ilma kodutundeta me jääme kodutuks. Kodutuse kogemuse kultuurifenomenoloogilise analüüsi katse. - Akadeemia, nr 3, lk 402-427.

Luks, Leo 2013b. Kas kodutus on moodsa aja normaalseisund? - Akadeemia, nr 6, lk 1111-1130.

Luks, Leo 2014. Eesti kirjanduse kadunud kodu. - Keel ja Kirjandus, nr 10, lk 729-748.

L u ks, Leo 2015. Nihilism ja kirjandus. Ei kogemine filosoofia ja kirjanduse ühtesulamisel. (ACTA Universitatis Tallinnensis.) Tallinn: Tallinna Ülikooli Kirjastus.

Luks, Leo 2016. 40 kiri. Tallinn: Eesti Keele Sihtasutus.

Malpas, Simon, W a ke, Paul (koost) 2015. Kriitilise teooria käsiraamat. (Gigantum Humeris.) Tallinn: Tallinna Ülikooli Kirjastus.

M a tj u s, Ülo 2012. Olemine kõneleb eesti keeli. Tartu: Ilmamaa. 
Raud, Rein 1995. Tühi maja. - Sõnarine. Eesti luule antoloogia. 4. köide. Koost

Karl Muru. Tallinn: Eesti Raamat, lk 523.

Ristikivi, Karl 1990. Inimese teekond. Tallinn: Eesti Raamat.

R unnel, Hando 1976. Mõru ning mööduja. Tallinn: Perioodika.

Steiner, George 2008. Meie kodumaa - tekst. - G. Steiner, Valik esseid. Tlk

Triinu Pakk. Loomingu Raamatukogu, nr 33-34. Tallinn: SA Kultuurileht, lk $45-70$.

S u u m a n, Aleksander 1977. Sõnad sulavad taevaga ühte. Tallinn: Eesti Raamat. Sööt, Karl Eduard 1968. Väike luuleraamat. Tallinn: Eesti Raamat.

Talivee, Elle-Mari 2009. Minek maalt linna. Kodu-käija staatus. - Minemise pidevus ja astumise katkendlikkus. Hando Runnel 70. Toim Õnne Kepp, Elo Lindsalu. Tallinn: Eesti Keele Sihtasutus, lk 53-64.

T a m m s a a r e, A. H. 1969. Tõde ja õigus V. Tallinn: Eesti Raamat.

Tee de, Andra 2014. 100\% andra teede. Saarde-Pärnu: Ji.

To m berg, Jaak, L o p p, Neeme 2008. Mis juhtub siis, kui tuleb meelde? - Ettekandepäeva „Unustuse arhiiv” avasõnad, kantud ette 25. aprillil Tartu Kirjanduse Maja krüptis. http://www.eki.ee/km/konv/unustus.htm (25. IX 2017).

Tuglas, Friedebert 1971. Kuldne rõngas. - F. Tuglas, Kogutud novellid. I kd. Tallinn: Eesti Raamat, lk 304-323.

V allak, Peet 1983. Hulkur. - P. Vallak, Hinge taud. Loomingu Raamatukogu, nr 22-23. Tallinn: Perioodika, lk 8-17.

Vallis o o, Mari 1995. Tuled koju. - Sõnarine. Eesti luule antoloogia. 4. köide.

Koost Karl Muru. Tallinn: Eesti Raamat, lk 499.

Vidler, Anthony 1987. The architecture of the uncanny: The unhomely houses of the romantic sublime. - Assemblage, nr 3, lk 6-29.

V i s n a p u u, Henrik 1964. Kogutud luuletused. I köide. Stockholm: Kirjastus Vaba Eesti.

Visnapuu, Henrik 1965. Kogutud luuletused. II köide. Stockholm: Kirjastus Vaba Eesti.

\section{Uncanny homecoming in Estonian literature}

Keywords: uncanny homecoming, Freud, phenomenology, Estonian literature

The article addresses homecoming as described in Estonian literature. First, a brief introduction is given to the theoretical foundations of the present approach to cosily settled vs. homeless, with references to some of the author's earlier publications. Speaking from experience, homecoming from afar is a festive, even solemn occasion - thus, its literary depiction should presumably use the festive register. The main argument of the article is that a typical case of homecoming in Estonian literature is associated with a home lost, due to which homecoming fails to meet the expectations of a celebration, turning instead into a weird, if not scary experience.

The theoretical basis of the article lies in Sigmund Freud's treatment of the uncanny (das Unheimliche). It is argued that Freud's approach is appropriate for the analysis of homecomings in Estonian literature. The theoretical introduction is followed by a parallel analysis of how homecoming is described in Estonian postwar exile literature and in homeland Estonian poetry. There follows a definition of 
the motifs of an eerie revenant and an empty house in Estonian literature (mainly based on Friedebert Tuglas' short story Kuldne rõngas ("Golden ring"). The article is concluded by an analysis of homecoming as a frustrating experience as depicted in Peet Vallak's short story Hulkur ("A vagabond") and in Merca's poem Saabumine ("Arrival").

The conclusive part of the article contains some rather far-reaching generalisations. It is argued that depiction of the cosy and the normal is not the mission of literature, which should instead generate malfunctions in the world of the everyday. It is doubted whether a literary work of high artistic value could ever be built on the sweet idyll of homecoming, which doubts are escalated in the following speculations about the onthology of literature and human nature. The article ends in a list of ways for the writer to avoid turning the description of a homecoming uncanny, namely, describe the homecoming as a process, but never depict the arrival.

Leo Luks (b. 1976), PhD, Estonian University of Life Sciences, Assistant Professor of Philosophy; Teacher of Philosophy at Herbert Masing School, Tartu, leoluks@hot.ee 